\title{
Efficient Production of Transgenic Soybean using a Co-transformation Method
}

\author{
Noriyuki Furutani*1) and Soh Hidaka ${ }^{2)}$ \\ 1) Kyoto Prefectural Institute of Agricultural Biotechnology, 74 Oaza Kitaine Yazuma, Seika, Soraku, Kyoto 619-0244, Japan \\ 2) National Agricultural Research Center for Tohoku Region, 4 Akahira, Shimokuriyagawa, Morioka, Iwate 020-0198, Japan
}

\begin{abstract}
Embryos of Glycine max (L.) Merrill cv. 'Jack' were cotransformed with the hygromycin phosphotransferase (hpt) gene and the jellyfish green fluorescent protein (GFP) gene by microprojectile bombardment. The purpose of this study was to determine the optimum conditions which could achieve the highest co-transformation rate using this method. In the whole process of cotransformation, the screening of transformants was effectively monitored by the expression of GFP. Transformation rates were highest when (1) induced embryos were transferred to a solid medium more than 5 times, (2) only the most highly-proliferated embryos forming globular clusters were bombarded, (3) the helium pressure of rupture disc was $1,100 \mathrm{psi}$, and (4) the embryogenic tissues 5 days after bombardment were cultured for more than 8 weeks in hygromycin-containing liquid medium for selection. In these conditions, the proportion of clones expressing hygromycin-resistance was $7 \%$, and the proportion of GFP-expressing clones was $18 \%$ of them.
\end{abstract}

Key Words: Glycine max, green fluorescent protein, microprojectile bombardment, soybean, co-transformation.

\section{Introduction}

Although several methods of transforming soybean have been reported (Christou et al. 1990, Finer and McMullen 1991, Finer et al. 1992, Sato et al. 1993, Hadi et al. 1996, Liu et al. 1996, Rong et al. 1996, Meurer et al. 1998, Santarem et al. 1998, Simmonds and Donaldson 2000), transformation of soybean is still time-consuming and the transformation rate is low. Recent studies indicate that two transformation techniques could be effective for more efficient production of transgenic soybean plants: Agrobacteriummediated DNA transfer (Trick and Finer 1998, Wang et al. 2001) and microprojectile bombardment of somatic embryogenic suspension cultures (Stewart et al. 1996, Samoylov et al. 1998). Although transgenic soybeans containing the target gene were produced by these methods, only a few viable transgenic lines could be generated.

Communicated by Y. Takahata

Received May 15, 2002. Accepted January 9, 2004.

*Corresponding author (e-mail: furutani@kab.seika.kyoto.jp)
We believe this is because transformation methods have not yet been properly quantified and established. To improve the efficiency of transformation, more appropriate and precise methods need to be developed. For monitoring the efficiency of each step, the jellyfish green fluorescent protein $(G F P)$ gene perfectly qualifies.

$G F P$ is a useful reporter gene. Several modified forms have been produced in order to obtain higher expression in plants, and have proved highly effective in transformation studies (Vain et al. 1998, Ponappa et al. 1999, Richard et al. 2001). In this study, among these various forms of the GFP gene, we chose sGFP (S65T) because it contains an engineered sequence that provides up to 100 -fold brighter fluorescence signals in plant and mammalian cells than does the original jellyfish GFP sequence (Niwa et al. 1999).

The objectives of this study were to develop a method for the co-transformation of soybean plants with the GFP and with the hygromycin phosphotransferase ( $h p t)$ genes. Co-transformation is one of the strategies that have been proposed to eliminate the presence of selectable marker genes in transgenic plants (Yoder and Goldsbrough 1994), and by inserting the transgenes at sufficiently unlinked loci, the target genes can be segregated from the selectable marker gene in the progenies (Daley et al. 1998, Donaldson and Simmonds 2000).

\section{Materials and Methods}

\section{Plasmid construction}

sGFP(S65T) was obtained from Dr. Y. Niwa as a 35Somega-sGFP(S65T) plasmid. The hpt gene, which was used as a selectable marker gene by conferring hygromycin resistance, was recloned into the $\mathrm{pE} 2113$ vector (Mitsuhara et al. 1996) from pWI-H5K (kindly supplied by Dr. M. Ugaki). This vector has two tandemly-repeated enhancerlike elements in the $5^{\prime}$-upstream region of the CaMV35S promoter, the $35 \mathrm{~S}$ core promoter, the $\Omega$ sequence, the polylinker sequence, and the terminator of the nos gene (Fig. 1).

\section{Induction and proliferation of embryos}

We used Glycine max (L.) Merrill cv. 'Jack', whose somatic embryos are comparatively easy to induce. Culture initiation and proliferation of embryos followed the methods of Finer and Nagasawa (1988). Immature cotyledons less than $10 \mathrm{~mm}$ in size were placed adaxial side down on MSD40 solid medium (Table 1), and only embryos were proliferated for 9 weeks with 2 transfers at intervals of 3 weeks. Globular embryo clusters were selected and 


\section{Somega-sGFP(S65T) plasmid}

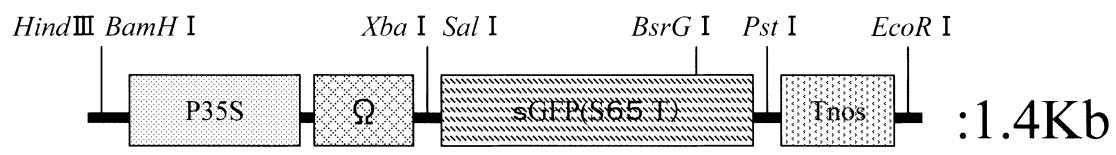

\section{pE2113 -HPT}

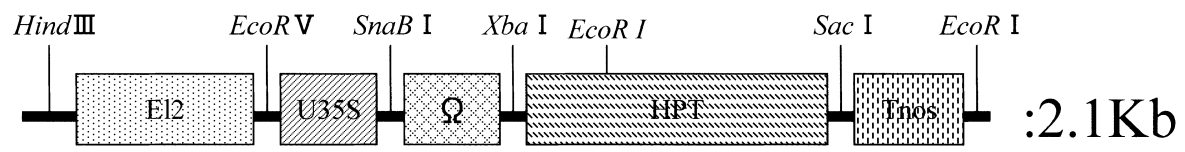

Fig. 1. Restriction maps of 35Somega-sGFP(S65T) plasmid and pE2113-HPT. E12: 5'-upstream sequence of the CaMV $35 \mathrm{~S}$ promoter $\times 2, \Omega$ : $5^{\prime}$-untranslated sequence of TMV, P35S: CaMV $35 \mathrm{~S}$ promoter, U35S: $5^{\prime}$-upstream sequence of the CaMV 35S promoter, Tnos: polyadenylation signal of the nopaline synthase gene of Agrobacterium tumefaciens Ti plasmid, sGFP: green fluorescent protein, HPT: hygromycin phosphotransferase.

transferred to MSD20 solid medium.

During the process of proliferation, some embryos formed callus or melted (Fig. 2d and 2e). Among the normally proliferated embryo clusters, only the clusters of compact embryos (shown in the circles of Fig. $2 \mathrm{a}$ and $2 \mathrm{~b}$ ) were transferred to the new solid medium at intervals of 3 weeks (Fig. $2 \mathrm{a}, 2 \mathrm{~b}, 2 \mathrm{c}, 2 \mathrm{f}$ and $2 \mathrm{~g}$ ). The culture conditions were $25^{\circ} \mathrm{C}$, and a $16-\mathrm{h}$ photoperiod with a light intensity of $5 \mu \mathrm{mol} \mathrm{m} \mathrm{m}^{-2} \mathrm{~s}^{-1}$.

\section{Microprojectile bombardment}

DNA for microprojectile bombardment was isolated using a Qiagen Plasmid Maxi kit (Qiagen, Santa Clarita, Cal.) according to the manufacturer's directions. Embryo clusters were bombarded using a PDS-1000/He particle delivery system as follows.

Two $\mu \mathrm{l} h p t$ plasmid DNA $(1 \mu \mathrm{g} / \mu \mathrm{l})$ and $2 \mu \mathrm{l} \mathrm{GFP} \mathrm{plas-}$ mid DNA $(1 \mu \mathrm{g} / \mu \mathrm{l})$ were added to $100 \mu \mathrm{l}$ of gold particles (Bio-Rad $1.6 \mu \mathrm{m}$ at $60 \mathrm{mg} / \mathrm{ml}$ ), to which was added $100 \mu \mathrm{l}$ of $2.5 \mathrm{M} \mathrm{CaCl}_{2}$, and then $40 \mu \mathrm{l}$ of $0.1 \mathrm{M}$ spermidine. The mixture was agitated for $30 \mathrm{~min}$, left for $30 \mathrm{~min}$, centrifuged for $3 \mathrm{sec}$ at 3,000 g, and then the supernatant was removed. The DNA-coated particles were washed twice in $600 \mu \mathrm{l}$ of $70 \%$ ethanol, and once in $600 \mu \mathrm{l}$ of $100 \%$ ethanol, and then resuspended in $100 \mu \mathrm{l}$ of $100 \%$ ethanol. Then, $10 \mu \mathrm{l}$ of the suspension was loaded onto each macrocarrier. Approximately 30 compact embryo clusters were placed over a $6 \mathrm{~cm}$-diameter circular area in the center of a Petri dish (Fig. 2h), and bombarded twice. A set of 5 dishes was considered as one experimental unit. The target distance was set at $9 \mathrm{~cm}$.

\section{Evaluation}

In order to estimate the effects of transformation methods on transformation rate, three main factors affecting transformation were evaluated (1) the frequency of embryo transfer to solid medium, (2) the duration of culture between transfer and bombardment, and (3) the helium pressure of rupture disc.
Embryos were transferred to the solid medium 3, 5, 7 or 9 times before bombardment, which was conducted under a helium pressure of 1,100 psi 7 days after transfer.

After embryo clusters were transferred to the final MSD20 solid medium, the effect of the culture duration in this medium was evaluated. Embryo clusters were bombarded on the day of the transfer, or at 7 or 14 days after the seventh transfer. Helium pressure was 1,100 psi.

Finally, the effect of the helium pressure was evaluated. Particles were accelerated using helium pressures of 900 , 1,100 and 1,350 psi, controlled using different rupture discs. Embryo clusters 7 days after the seventh transfer were used.

\section{Selection of transformants}

Transformants were selected 5 days after bombardment. A group of 4 embryogenic tissues (Fig. 2h) were transferred to a $100 \mathrm{~mm} \times 100 \mathrm{~mm}$ culture bottle containing $50 \mathrm{ml}$ FNL liquid medium (Table 1). Each medium was replaced every week, and the hygromycin concentration was raised with each replacement, firstly from $15 \mathrm{mg} / \mathrm{l}$ (twice) to $20 \mathrm{mg} / \mathrm{l}$ (twice) and then to $30 \mathrm{mg} / \mathrm{l}$ (4 times).

After 8 weeks of culture, although almost all the embryos became white, several green embryogenic clones were observed (Fig. 3a). These were transferred to FNL0S3 medium (Table 1). We recognized these selected embryogenic clones as independent lines of transformants. After another 3 weeks, the selected embryogenic clones were transferred to fresh FNLOS3 medium where they were allowed to histodifferentiate and mature (Fig. 3b). Each embryo derived from an embryogenic cluster was placed on an empty Petri dish to desiccate. A week later, germination was induced by culturing desiccated embryos on MS0 medium.

\section{Monitoring of sGFP (S65T) expression by microscope}

An OLYMPUS IX70-FLA fluorescent microscope equipped with a GFPA filter (excitation filter 460-490 nm; emission barrier filter $510-550 \mathrm{~nm}$ ) was used to observe the 

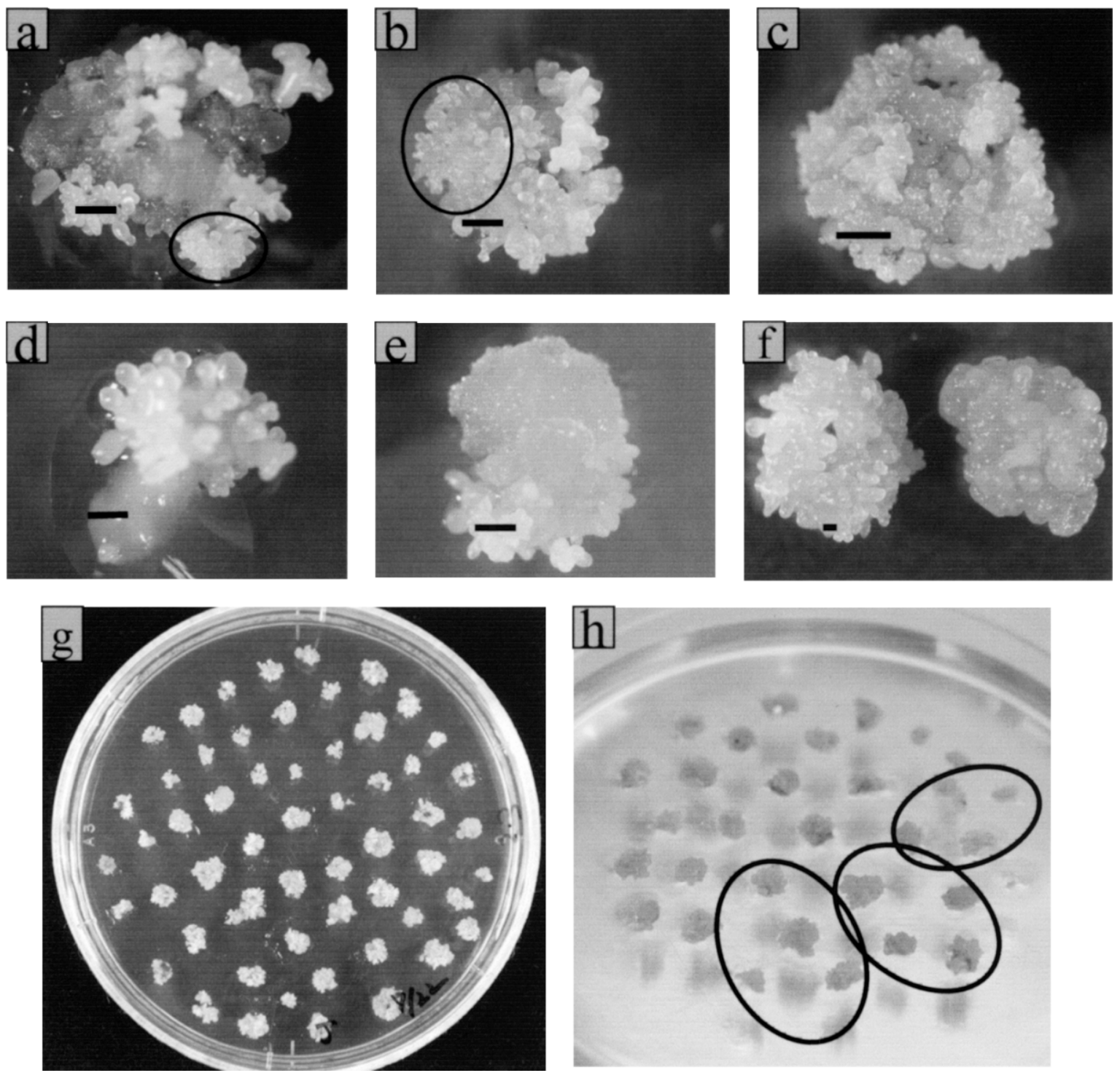

Fig. 2. Induction and proliferation of embryos. (a) Immature cotyledons on MSD40 solid medium (adequate clusters for transfer shown in the circle). (b) Embryo clusters transferred to solid medium 3 times (adequate clusters for transfer shown in the circle). (c) Embryo clusters transferred to solid medium 5 times. (d) Melted embryo clusters. (e) Callus-forming embryo clusters. (f) Embryo clusters maintained for 3 weeks on MSD20 medium (left), or in FNL liquid medium (right). (g) Embryo clusters maintained on MSD20. medium. (h) Embryo clusters ready for bombardment (circle indicates a set of $4 \mathrm{em}-$ bryogenic tissues ready for selection). The bars indicate a distance of $2.0 \mathrm{~mm}$.

levels of sGFP (S65T) expression in embryogenic tissues and regenerated plants.

\section{PCR and Southern blot hybridization analysis}

DNA was extracted from leaves of putative transformants and non-transformed plants (50 $\mathrm{mg}$ fresh weight), using a Qiagen DNeasy kit according to the manufacturer's directions. For PCR analysis, GFP gene-specific primers [forward (5'-GCAAGACCCTTCCTCTATATAAGG-3') and reverse (5'-CTTGTACAGCTCGTCCATGCC-3')] were designed to amplify an $849 \mathrm{bp}$ fragment including the coding region. Conditions for the thermal cycle were, step $1: 94^{\circ} \mathrm{C}$ for $5 \mathrm{~min}$; step 2 ( 30 cycles): $94^{\circ} \mathrm{C}$ for $1 \mathrm{~min}, 57^{\circ} \mathrm{C}$ for $2 \mathrm{~min}$ and $72^{\circ} \mathrm{C}$ for $2 \mathrm{~min}$; step $3: 72^{\circ} \mathrm{C}$ for $7 \mathrm{~min}$.

$H P T$ gene-specific primers [forward (5'-TGCGGGTAA $\left.A T A G C T G C G C-3^{\prime}\right)$ and reverse (5'-AACATCGCCTCGCTC $\left.\left.C A G T-3^{\prime}\right)\right]$ were designed to amplify a $523 \mathrm{bp}$ internal fragment of the coding region. Conditions for the thermal cycle were, step 1: $94^{\circ} \mathrm{C}$ for $5 \mathrm{~min}$; step 2 ( 30 cycles): $94^{\circ} \mathrm{C}$ for $1 \mathrm{~min}, 55^{\circ} \mathrm{C}$ for $2 \mathrm{~min}$ and $72^{\circ} \mathrm{C}$ for $2 \mathrm{~min}$; step $3: 72^{\circ} \mathrm{C}$ for 7 min.

For Southern blot analysis, DNA was extracted from young leaves of $\mathrm{T}_{1}$ plants (100 mg fresh weight), using a Qiagen DNeasy kit. After DNA was digested with EcoRI, 5 $\mu \mathrm{g}$ of DNA was electrophoresed through a $1.0 \%$ agarose gel and blotted onto a nylon membrane Hybond-N+ (Amersham 

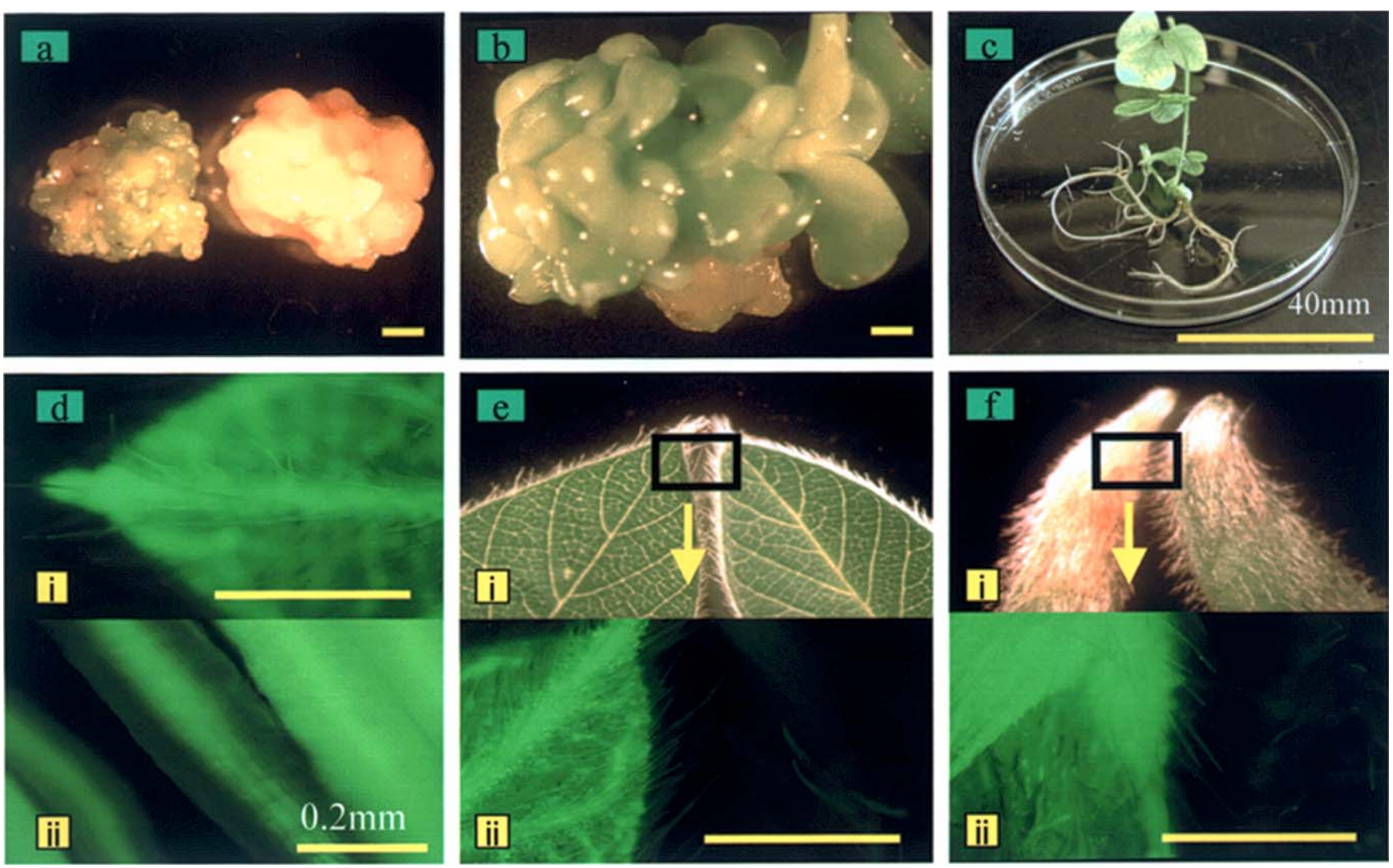

Fig. 3. Histodifferentiation of transformants and expression of GFP in (a) Hygromycin-resistant embryogenic tissue (left) and sensitive tissue (right). (b) Hygromycin-resistant tissue after histodifferentiation. (c) Transgenic soybean plant. (d) Transgenic soybean plant (T0): leaf (i) and roots (ii) visualized under UV. (e) Transgenic soybean plant leaf $\left(\mathrm{T}_{1}\right)$ : transformant (left), non-transformant (right), (ii) plants visualized under UV. (f) Transgenic soybean plant pod $\left(\mathrm{T}_{2}\right)$ : transformant (left), non-transformlant (right), (ii) plants visualized under UV. The bars indicate $1.0 \mathrm{~mm}$ in a,b,d (i), e (ii) and $\mathrm{f}$ (ii).

Pharmacia Biotech UK Ltd.). Labeling of the PCR-amplified GFP sequence containing the whole coding region (720 bp) as a probe, hybridization and detection were performed using an 'Alkphos Direct Labeling Kit' and 'Detection System with CDP-Star' (Amersham Pharmacia Biotech UK Ltd.) according to the instruction manuals.

\section{Results}

\section{Transient expression of GFP}

Transient expression of GFP was observed using a microscope. The number of visible GFP-expressing cells in embryogenic tissues was counted. GFP expression in embryogenic tissue was first observed 3 or 4 hours after bombardment on the final MSD20 solid medium. At 14 hours after bombardment, many GFP-expressing cells were observed (Fig. 4). The number of GFP-expressing cells gradually decreased over time, and very few cells were observed after 13 days ( $312 \mathrm{~h}$ ) post-bombardment (Fig. 5 and Fig. 6). The effect of culture duration on the transient expression of GFP is shown in Figure 5. Embryogenic tissues cultured for 14 days before bombardment had the greater number of GFPexpressing cells, and those bombarded just after transfer had a few expressing cells. The helium pressure of rupture disc
Table 1. Composition of the media used for soybean somatic embryogenesis

\begin{tabular}{ll}
\hline \hline Medium & Composion \\
\hline FN Lite basal & FN Lite macro salts (Samoylov et al. 1998), \\
& MS micro salts (Murashige and Skoog 1962), \\
& B5 vitamins (Gamborg et al. 1968), $6.7 \mathrm{mM}$, \\
& L-asparagine, pH 5.8
\end{tabular}

FNL FN Lite basal medium, 22.6M (5 mg/l) 2,4-D, $29.2 \mathrm{mM}(1 \% \mathrm{wt} / \mathrm{vol})$ sucrose (Samoylov et al. 1998)

FNL0S3 FN Lite basal medium, $87.6 \mathrm{mM} \mathrm{(3 \% wt/vol)}$ sucrose

MS0 MS basal salts, B5 vitamins, $87.6 \mathrm{mM}(3 \% \mathrm{wt} / \mathrm{vol})$ sucrose, $\mathrm{pH} 5.8,0.2 \%$ Gelrite

MSD20 $\quad$ MS basal salts, B5 vitamins, $90.4 \mu \mathrm{M}(20 \mathrm{mg} / \mathrm{l})$

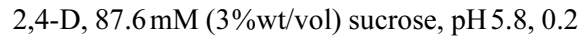
$\%$ Gelrite

MSD40 MS basal salts, B5 vitamins, $180.8 \mu \mathrm{M}(40 \mathrm{mg} / \mathrm{l})$ 2,4-D, 87.6 mM (3\%wt/vol) sucrose, $\mathrm{pH} 5.8,0.2$ $\%$ Gelrite 


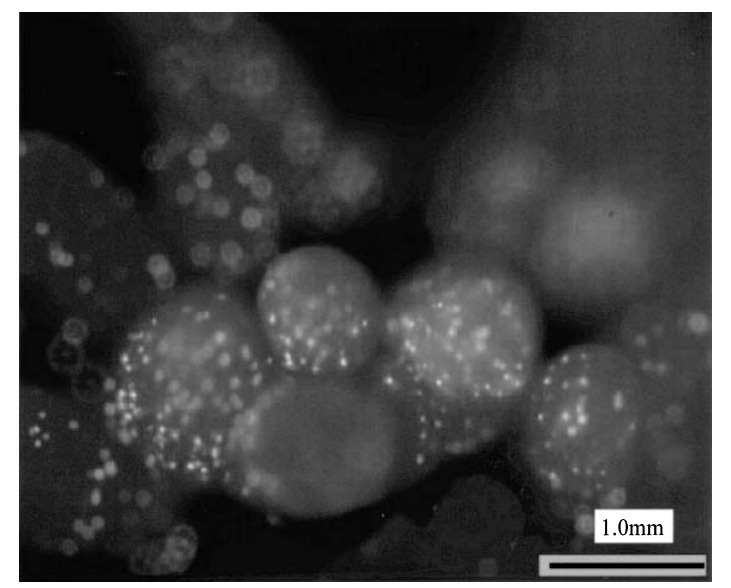

Fig. 4. Expression of sGFP(S65T) in a soybean embryogenic tissue on MSD20 medium 14 $\mathrm{h}$ post-bombardment.

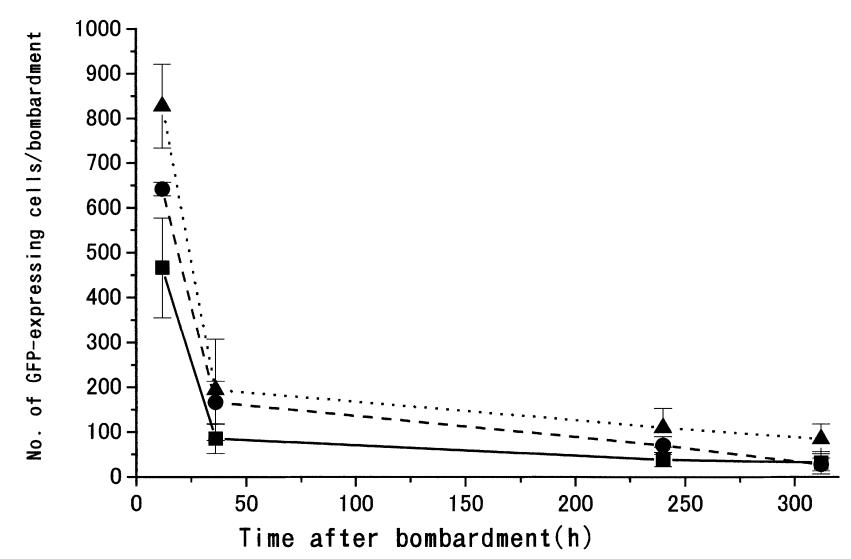

Fig. 5. Effect of ante-bombardment-embryo culture duration after the seventh transfer on GFP expression in embryogenic tissues. Culture duration $0(\mathbf{\square}), 7(\mathbf{O})$ or $14(\mathbf{\Delta})$ days. Embryogenic tissues were bombarded at rupture disc helium pressure of 1,100 psi. Each points represents the mean \pm SE for $n=3$ bombardments. Number of cells is the amount of fluorescing cells observed in 5 clumps of embryogenic tissue.

affected the transient expression of GFP (Fig. 6). The number of visible cells expressing GFP per embryogenic tissue was much greater at 1,100 and 900 psi than at 1,350 psi. The number of GFP-expressing cells 10 days post-bombardment was greater at $1,100 \mathrm{psi}$ than at 900 psi. There were a few GFP-expressing cells at $1,350 \mathrm{psi}$, and they were hardly visible 36 hours post-bombardment.

\section{Conditions for the higher transformation rate}

Embryogenic tissues co-transformed with the GFP and hpt genes were selected in the hygromycin-containing liquid medium. Embryogenic clones were obtained after approximately 8 weeks of suspension culture (Fig. 3a). They proceeded to the stages of histodifferentiation and germination (Fig. 3b and 3c). In order to achieve efficient and stable transformation with a high transformation rate, we examined the three main factors of transformation, which are consid-

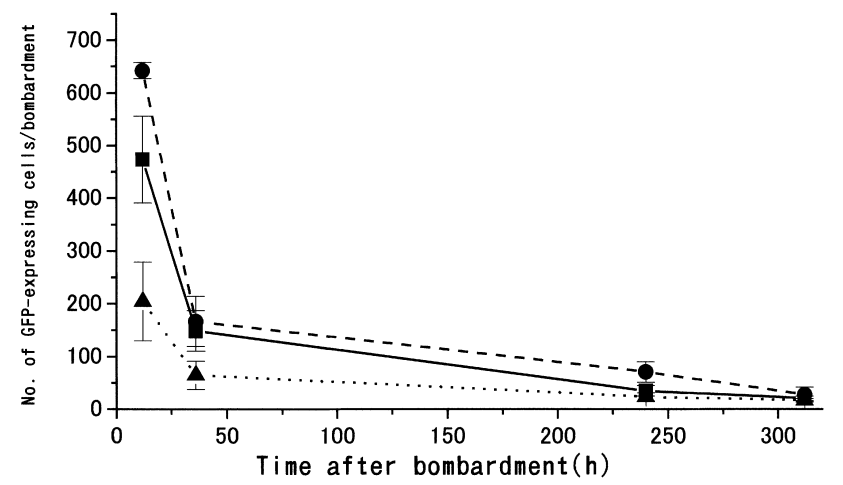

Fig. 6. Effect of helium pressure of rupture disc on GFP expression in embryogenic tissues. The embryos cultured for 7 days after the seventh transfer were bombarded. Disc pressures were 900 (), 1,100 ( $)$ and 1,350 psi $(\boldsymbol{\Delta})$. Each point represents the mean \pm SE for $n=3$ bombardments. Number of cells is the amount of cells observed in 5 clumps of embryogenic tissues.

ered to affect directly the success of transformation. They are the number of transfers, the culture duration and the helium pressure of rupture disc.

In the cases when globular embryo clusters were transferred 3 times before bombardment, the transformed tissues were hardly produced. However, when globular embryo clusters were transferred more than 5 times, the transformation rate reached $7 \%$. This rate was maintained even with the embryos that were transferred 9 times before bombardment, i.e., 27 weeks post-induction (Table 2).

Regarding the culture duration on the final MSD20 solid medium, the transformation rate was significantly higher with the embryos cultivated for 7 or 14 days before bombardment, compared with those bombarded soon after the transfer (Table 3).

The helium pressure was also the key for the efficient transformation. The transformation rate of embryo clusters bombarded at the helium pressures of 900 or 1,100 psi was higher than that of those bombarded at 1,350 psi (Table 4).

\section{Stable transformation}

In our experiments conducted under the conditions of 7 or 14 days of culture durations using a helium pressure of 1,100 psi, 62 hygromycin-resistant embryogenic clones were obtained from 864 embryogenic tissues bombarded (Table 5). Among these selected embryogenic clones, 39 plantlets were regenerated.

$\mathrm{T}_{0}$ and $\mathrm{T}_{1}$ plants reached maturity and set seeds normally (Fig. 7). The presence of the introduced genes in regenerated plants was confirmed by PCR analysis. The presence of hpt gene was confirmed in all 39 regenerated soybean plants (Fig. 8) and 7 plants expressed GFP (Table 5).

Southern blot hybridization analysis showed that $T_{1}$ plants contained 1 to 4 copies of GFP gene (Fig. 9). GFP expression was also observed in leaves, roots and pods of $\mathrm{T}_{0}, \mathrm{~T}_{1}$ and $\mathrm{T}_{2}$ plants (Fig. 3d, 3e and 3f). Transformed plants expressing GFP were produced constantly in each 
Table 2. The effect of ante-bombardment-embryo-transfer on the transformation rate

\begin{tabular}{cccc}
\hline \hline $\begin{array}{c}\text { No. of embryo transfers } \\
\text { (times) }\end{array}$ & $\begin{array}{c}\text { No. of embryogenic tissues } \\
\text { bombarded }\end{array}$ & $\begin{array}{c}\text { Hygromycin-resistant clones }{ }^{1)} \\
(\%)\end{array}$ & $\begin{array}{c}\text { GFP-expressed clones }{ }^{2} \\
(\%)\end{array}$ \\
\hline 3 & 288 & $0.4 \mathrm{a}^{3)}$ & 0.0 \\
5 & 288 & $6.6 \mathrm{~b}$ & 1.4 \\
7 & 288 & $7.3 \mathrm{~b}$ & 1.4 \\
9 & 288 & $7.7 \mathrm{~b}$ & 1.0 \\
\hline
\end{tabular}

1) Percentage of hygromycin-resistant clones as average of three replications with 96 embryogenic tissues.

2) Percentage of GFP-expressed clones as average of three replications with 96 embryogenic tissues.

3) Means followed by the same letters are not significantly different by chi-square test with a Bonferroniadjusted at least $5 \%$ level. Embryo tissues cultured for 7 days after transfer were bombarded at a helium pressure of 1,100 psi.

Table 3. The effect of ante-bombardment-embryo culture duration after the seventh transfer on the transformation rate

\begin{tabular}{cccc}
\hline \hline Culture duration (days) & $\begin{array}{c}\text { No. of embryogenic tissues } \\
\text { bombarded }\end{array}$ & $\begin{array}{c}\text { Hygromycin-resistant clones }{ }^{1)} \\
(\%)\end{array}$ & $\begin{array}{c}\text { GFP-expressed clones }{ }^{2)} \\
(\%)\end{array}$ \\
\hline 0 & 288 & $2.8 \mathrm{a}^{3}$ & 0.4 \\
7 & 288 & $7.3 \mathrm{~b}$ & 1.4 \\
14 & 288 & $7.6 \mathrm{~b}$ & 1.0
\end{tabular}

1) Percentage of hygromycin-resistant clones as average of three replications with 96 embryogenic tissues.

2) Percentage of GFP-expressed clones as average of three replications with 96 embryogenic tissues.

3) Means followed by the same letters are not significantly different by chi-square test with a Bonferroniadjusted at least $5 \%$ level. Embryo tissues after seventh transfer were bombarded at a pressure of $1,100 \mathrm{psi}$ of helium.

Table 4. The effect of helium pressure of rupture disc on the transformation rate

\begin{tabular}{cccc}
\hline \hline Rupture Disc (psi) & $\begin{array}{c}\text { No. of embryogenic tissues } \\
\text { bombarded }\end{array}$ & $\begin{array}{c}\text { Hygromycin-resistant clones }{ }^{1)} \\
(\%)\end{array}$ & $\begin{array}{c}\text { GFP-expressed clones }{ }^{2)} \\
(\%)\end{array}$ \\
\hline 900 & 288 & $6.9 \mathrm{a}^{3)}$ & 1.0 \\
1100 & 288 & $7.3 \mathrm{a}$ & 1.4 \\
1350 & 288 & $3.5 \mathrm{~b}$ & 0.3 \\
\hline
\end{tabular}

1) Percentage of hygromycin resistant clones as average of three replications with 96 embryogenic tissues.

2) Percentage of GFP-expressed clones as average of three replications with 96 embryogenic tissues.

3) Means followed by the same letters are not significantly different by chi-square test with a Bonferroniadjusted at least 5\% level. Embryo tissues cultured for 7 days after seventh transfer were bombarded.

experimental unit. These results indicated the efficiency of our co-transformation method of introducing a particular gene into soybean plants.

\section{Discussion}

\section{Transformation rate}

Although there are numerous reports on the successful production of transformed soybean using microprojectile bombardment method, the transformation rates in those studies were modest and time-consuming. Also, these reports are rather deficient in detailed data about the experimental conditions for transformation (Stewart et al. 1996, Samoylov et al. 1998). At the early stage of our study, we considered that the helium pressure and the target distance were keys for the success of transformation, and sufficient consideration was not given to the number of transfers and the culture duration. Consequently we obtained the hygro- mycin resistant clones in only 2 out of 18 experimental units, and the transformation rate was lower than $1 \%$.

In this study, we examined the proliferation method of embryo cluster and gene introduction in order to determine the optimum conditions for obtaining the highest transformation rate.

In the report of Samoylov et al. (1998), embryos were bombarded on MSD solid medium after they were transferred from FNL liquid medium in which they had been maintained for 9 months. In our method, the maintenance period before bombardment is shortened to 4 months (Table 2), and both maintenance culture and bombardment were performed on the same solid medium. Also, after transfer to solid medium embryos became more compact and smaller (Fig. 2f). We consider that this tightly-packed structure of embryos raises the bombardment efficiency, and conclusively contributes to the higher transformation rate.

Two other factors were found to affect the transformation 
Table 5. The transformation rate of embryogenic tissues bombarded under the optimum conditions ${ }^{1)}$

\begin{tabular}{cccccc}
\hline \hline \multirow{2}{*}{$\begin{array}{c}\text { No. of embryogenic } \\
\text { tissues bombarded }\end{array}$} & \multicolumn{2}{c}{ No. of clones } & & \multicolumn{2}{c}{ No. of regenerated plants } \\
\cline { 2 - 3 } \cline { 5 - 6 } & $\begin{array}{c}\text { Hygromycin-resistant } \\
(\%)\end{array}$ & $\begin{array}{c}\text { GFP-expressed } \\
(\%)\end{array}$ & & $\begin{array}{c}\text { Hygromycin-resistant } \\
(\%)\end{array}$ & $\begin{array}{c}\text { GFP-expressed } \\
(\%)\end{array}$ \\
\hline 864 & 62 & 11 & 39 & 7 \\
& $(7.2)$ & $(1.3)$ & & $(4.5)$ & $(0.8)$ \\
\hline
\end{tabular}

1) These results were calculated from the data obtained with 5 times of embryo transfer in Table 2 and data of 7 and 14 days of culture duration in Table 3, because frequency of plant regeneration was examined in these experiments.

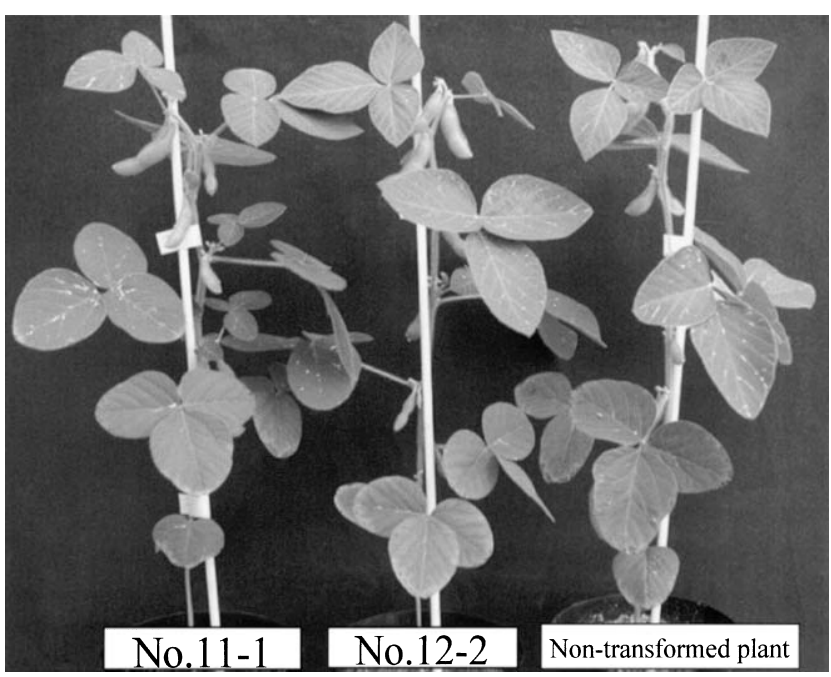

Fig. 7. Transformed lines (T1) and non-transformed plant (cv. Jack) No. 11-1 and No 12-2: transformed lines.

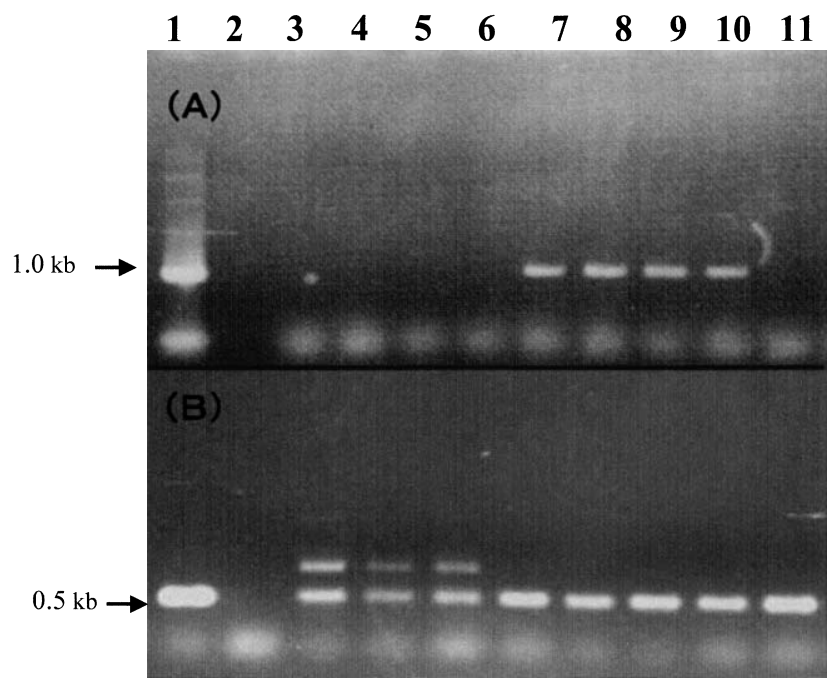

Fig. 8. Transformed lines $\left(\mathrm{T}_{0}\right)$ and non-transformed plant (cv. Jack). PCR analysis of DNA isolated from leaves of $\mathrm{T}_{0}$ plants. GFP gene (A) and hpt gene (B) amplified by PCR. Lane 1: plasmid (positive control), Lane 2: non-transformed (negative control), Lane3-11: regenerated $\mathrm{T}_{0}$ plants.

rate. The first was the culture duration before bombardment. The transformation rate and transient expression of GFP were highest when embryo clumps were bombarded 7 or 14 days post-transfer, the period of most active embryo prolifer-

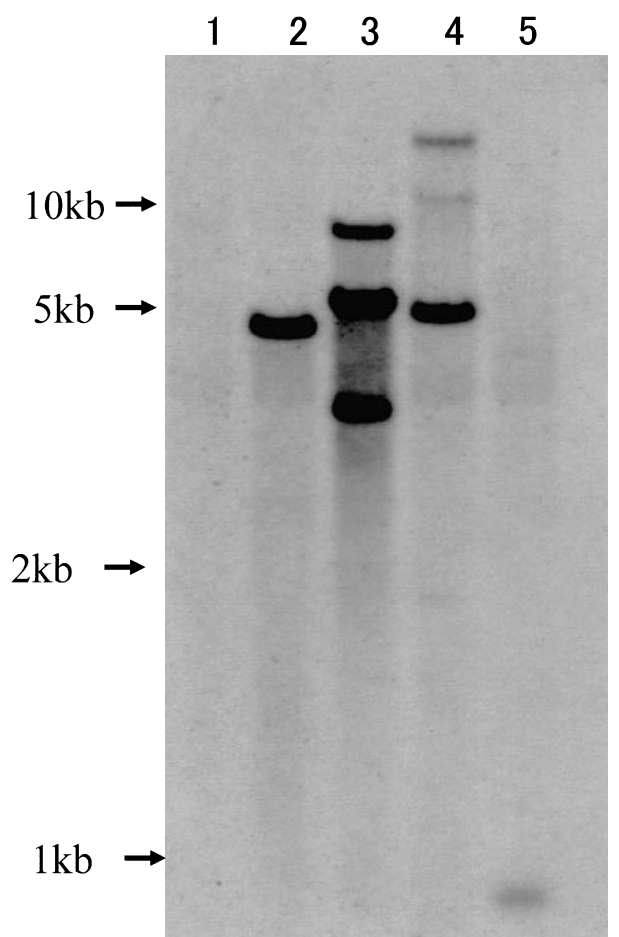

Fig. 9. Southern blot analysis of EcoRI-digested total DNA probed with on GFP fragment in transformed plants. Lane 1: nontransformed plant (cv. Jack); 2: No. 12; 3: No. 32; 4: No. 73; and 5: No. 113.

ation. The second factor was the helium pressure of microprojectile bombardment. Bombardment at the pressure of 1,100 psi resulted in the higher transformation rate and GFP expression.

We considered that microprojectile bombardment method risks damaging embryo clumps, especially at a rupture disc helium pressure of 1,350 psi. The lower transformation rate and GFP expression of embryogenic tissues bombarded using this pressure confirms this.

In conclusion, the optimum embryo formation for gene introduction is a compact and actively proliferating clump that was selected after more than 5 times of transfers since the induction from the immature cotyledons. Particle bombardment should be conducted at the rupture disc helium pressure of $1,100 \mathrm{psi}$, using embryo clumps that have not been recently transferred at least 7 days so that they can be in the most active proliferation stage. Under these conditions, we obtained the highest transformation rate of $7 \%$. 


\section{Co-transformation}

We approved the significance of co-transformation, as well as the pursuit of the higher transformation rate in soybean plant. In present study, we co-transformed soybean embryos with the selectable marker gene hpt and the GFP gene as a model of target genes. Among 864 embryogenic tissues bombarded under the optimum conditions, 62 hygromycinresistant clones were selected in the liquid medium, and 11 of them also expressed the co-transformed GFP gene. Approximately $63 \%$ of the hygromycin-resistant clones produced in this study regenerated normally. All the regenerated plants contained the hpt gene, and $18 \%$ of them also expressed GFP. This is $0.8 \%$ of the rate for all the cotransformed embryogenic tissues. Considering the massiveness of embryos that can be co-transformed and selected, this rate is sufficiently high. GFP expression was normal in $\mathrm{T}_{0}, \mathrm{~T}_{1}$, $\mathrm{T}_{2}$ and $\mathrm{T}_{3}$ plants, and the plants grew and set seed normally.

We believe this co-transformation method will enable the introduction of any genes into soybean plants with a high probability and the transformed soybean progenies will express only the target gene, which is segregated from a selectable marker gene.

\section{Acknowledgements}

We thank Dr. Y. Niwa for supplying sGFP (S65T), Dr. T. Hagio for his helpful suggestions, and Ms. N. Yamagishi for technical assistance. This work was funded by the Kyoto Prefectural Government and the Ministry of Agriculture, Forestry and Fisheries.

\section{Literature Cited}

Christou,P., D.E.McCabe, B.J.Martinell and W.Swain (1990) Soybean genetic engineering-commercial production of transgenic plants. TIBTECH 8: 145-151.

Daley,M., V.C.Knauf, K.R.Summerfelt and J.C.Turner (1998) Cotransformation with one Agrobacterium tumefaciens strain containing two binary plasmids as a method for producing markerfree transgenic plants. Plant Cell Rep. 17: 489-496.

Donaldson, P.A. and D.H.Simmonds (2000) Susceptibility to Agrobacterium tumefaciens and cotyledonary node transformation in short-season soybean. Plant Cell Rep. 19: 478-484.

Finer,J.J. and A.Nagasawa (1988) Development of an embryogenic suspension culture of soybean (Glycine max Merrill.). Plant Cell Tissue Organ Cult. 15: 125-136.

Finer,J.J. and M.D.McMullen (1991) Transformation of soybean via particle bombardment of embryogenic suspension culture tissue. In Vitro Cell Dev. Biol. 27: 175-182.

Finer,J.J., P.Vain, M.W.Jones and M.D.McMullen (1992) Development of the particle inflow gun for DNA delivery to plant cells. Plant Cell Rep. 11: 323-328.

Gamborg,O.L., R.A.Miller and K.Ojima (1968) Nutrient requirements of suspension culture of soybean root cells. Exp Cell Res. 50: 150-158.

Hadi,M.Z., M.D.McMullen and J.J.Finer (1996) Transformation of 12 different plasmids into soybean via particle bombardment. Plant Cell Rep. 15: 500-505.
Liu, W., R.S.Torisky, K.P.McAllister, S.Avdiushko, D. Hildebrand and G.B.Collins (1996) Somatic embryo cycling: evaluation of a novel transformation and assay system for seed-specific gene expression in soybean. Plant Cell Tissue Organ Cult. 47: 33-42.

Meurer,C.A., R.D.Dinkins and G.B.Collins (1998) Factors affecting soybean cotyledonary node transformation. Plant Cell Rep. 18: 180-186.

Mitsuhara,I., M. Ugaki, H. Hirochika, M. Ohshima, T. Murakami, Y.Gotoh, Y.Katayose, S.Nakamura, R.Honkura, S.Nishimiya, K.Ueno, A.Mochizuki, H.Tanimoto, H.Tsugawa, Y.Otsuki and Y.Ohashi (1996) Efficient promoter cassettes for enhanced expression of foreign genes in dicotyledonous and monocotyledonous plants. Plant Cell Physiol. 37: 49-59.

Murashige,T. and F.Skoog (1962) A revised medium for rapid growth and bioassays with tobacco tissue cultures. Physiol. Plant. 15: 473-497.

Niwa, Y., T.Hirano, K. Yoshimoto, M.Shimizu and H.Kobayashi (1999) Non-invasive quantitative detection and applications of non-toxic, S65T-type green fluorescent protein in living plants. Plant J. 18: 455-463.

Ponappa,T., A.E.Brzozowski and J.J.Finer (1999) Transient expression and stable transformation of soybean using the jellyfish green fluorescent protein. Plant Cell Rep. 19: 6-12.

Richard,H.A., V.A.Rudas, H.Sun, J.K.Mcbaniel, Z.Tomaszewski and B.V.Conger (2001) Construction of GFP-BAR plasmid and its use for switchgrass transformation. Plant Cell Rep. 20: 48-54.

Rong,D., P.Virginia, B.C.Glenn and A.G.Said (1996) Production of transgenic soybean lines expressing the bean pod mottle virus coat protein precursor gene. Plant Cell Rep. 15: 746-750.

Samoylov, V.M., D.M.Tucker, F.Thibaud-Nissen and W.A.Parrott (1998) A liquid-medium-based protocol for rapid regeneration from embryogenic soybean cultures. Plant Cell Rep. 18: 49-54.

Santarem,E.R., H.N.Trick, J.S.Essig and J.J.Finer (1998) Sonicationassisted Agrobacterium-mediated transformation of soybean immature cotyledons: optimization of transient expression. Plant Cell Rep. 17: 752-759.

Sato,S., C.Newell, K.Kolacz, L.Tredo, J.Finer and M.Hinchee (1993) Stable transformation via particle bombardment in two different soybean regeneration systems. Plant Cell Rep. 12: 408-413.

Simmonds,D.H. and P.A.Donaldson (2000) Genotype screening for proliferative embryogenesis and biolistic transformation of short-season soybean genotypes. Plant Cell Rep. 19: 485-490.

Stewart, C.N.Jr., M.J.Adang, J.N.All, H.R.Boerma, G.Cardineau, D. Tucker and W.A.Parrott (1996) Genetic transformation, recovery, and characterization of fertile soybean transgenic for a synthetic Bacillus thuringiensis crylAC gene. Plant Physiol. 112: 121-129.

Trick,H.N. and J.J.Finer (1998) Sonication-assisted Agrobacteriummediated transformation of soybean [Glycine $\max (\mathrm{L}$.$) Merrill]$ embryogenic suspension culture tissue. Plant Cell Rep. 17: 482-488.

Vain,P., B.Worland, A.Kohli, J.W.Snape and P.Christou (1998) The green fluorescent protein (GFP) as a vital screenable marker in rice transformation. Theor. Appl. Genet. 96: 164-169.

Wang, X., A.L.Eggenberger, F.W.Nutter Jr. and J.H.Hill (2001) Pathogen-derived transgenic resistance to soybean mosaic virus in soybean. Mol. Breed. 8: 119-127.

Yoder,J.I. and A.P.Goldsbrough (1994) Transformation systems for generating marker-free transgenic plants. Bio/Technology 12: 263-267. 